\title{
Disseminação de informações sobre primeiros socorros e prevenção de acidentes em uma comunidade ribeirinha
}

\section{Dissemination of information on first aid and accident prevention in a riverside community}

\section{Diseminación de informaciones de primeros auxilios y prevención de accidentes en una comunidad ribereña}

\author{
Maria Giovana Queiroz de Lima iD \\ Universidade Federal do Amazonas - Manaus (AM) - Brasil \\ Luma Ximenes de Oliveira iD \\ Universidade Federal do Amazonas - Manaus (AM) - Brasil \\ Amanda Ellen de Morais iD \\ Universidade Federal do Amazonas - Manaus (AM) - Brasil
}

Bruna Natália Serrão Lins Pinto iD

Universidade Federal do Amazonas - Manaus (AM) - Brasil

Laísa Ezaguy de Hollanda (iD

Universidade Federal do Amazonas - Manaus (AM) - Brasil

Ronaldo Almeida Lidório Júnior (iD

Universidade Federal do Amazonas - Manaus (AM) - Brasil

\section{RESUMO}

Objetivo: Relatar a experiência de um projeto de extensão universitária acerca de primeiros socorros e prevenção de acidentes em uma ação de capacitação da população ribeirinha. Síntese de dados: Trata-se de um relato de experiência vivenciada em outubro de 2015 por acadêmicos de Medicina de uma universidade da região Norte do Brasil, integrantes de um projeto de extensão universitária, que foram convidados pela Defesa Civil do município para instruírem, por meio de palestras e atividades práticas sobre primeiros socorros e prevenção de acidentes, os moradores da comunidade ribeirinha Santa Maria do Rio Negro (Manaus, Amazonas, Brasil). Conclusão: O projeto de extensão universitária proporcionou aos acadêmicos a interação com a população ribeirinha em questão, oportunizando, por meio de atividades educativas de prevenção e simulação, a capacitação para a ação mais preparada em situações de emergência, a contribuição do ensino médico às necessidades de saúde pública e o fortalecimento do papel do médico na promoção da saúde.

Descritores: Primeiros socorros; Ensino; Promoção da Saúde; Medicina; Estudantes de Ciências da Saúde.

\begin{abstract}
Objectives: To report the experience of a university extension project about first aid and accident prevention in a training activity for the riverside population. Synthesis of data: This is a reported experience lived in October 2015 by medical students from a university in the northern region of Brazil, members of a university extension project, who were invited by the municipality's Civil Defense to instruct, for example, through lectures and practical activities on first aid and accident prevention, residents of the riverside community Santa Maria do Rio Negro (Manaus, Amazonas, Brazil). Conclusion: The university extension project provided the students with the interaction with the riverside population in question, providing, through educational activities of prevention and simulation, the training for the most prepared action in emergencies, the contribution of medical education to the needs public health and strengthening the physicianss role in health promotion.
\end{abstract}

Descriptors: First Aid; Teaching; Health Promotion; Medicine; Students, Health Occupation.

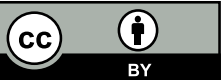




\section{RESUMEN}

Objetivo: Relatar la experiencia de un proyecto de extensión universitaria sobre los primeros auxilios y la prevención de accidentes en una acción de capacitación de la población ribereña. Síntesis de datos: Se trata de un relato de experiencia de octubre de 2015 por los estudiantes de Medicina de una universidad de la región Norte de Brasil que participaban de un proyecto de extensión universitaria y que han sido invitados por la Defensa Civil del municipio para pasar informaciones de primeros auxilios y prevención de accidentes para personas de la comunidad ribereña Santa María de Río Negro (Manaus, Amazonas, Brasil) a través de ponencias y actividades prácticas. Conclusión: El proyecto de extensión universitaria ha permitido a los estudiantes la interacción con esa población ribereña ofreciendo la oportunidad a través de actividades educativas de prevención y simulación, la capacitación para la acción más preparada en el caso de situaciones de emergencia, la contribución de la enseñanza médica para las necesidades de salud pública y el fortalecimiento del papel del médico para la promoción de la salud.

Descriptores: Primeros Auxilios; Enseñanza; Promoción de la Salud; Medicina; Estudiantes del Área de la Salud.

\section{INTRODUÇÃO}

As populações ribeirinhas da Amazônia são representadas por grupos sociais distintos (indígenas, nordestinos, migrantes de outras regiões), os quais vivem às margens dos rios e lagos da região amazônica. Por esse motivo, seu modo de viver segue a dinâmica das águas - períodos de cheia ou vazante -, o que lhes impõe certas restrições, dificultando o acesso à saúde e, até mesmo, a informações sobre saúde ${ }^{(1)}$.

Como qualquer população, os ribeirinhos estão sujeitos ao adoecimento por doenças infecciosas, crônicas ou causas externas. As causas externas são traumatismos ou lesões consequentes de violência ou outra causa exógena. Podem ser citados: afogamentos, engasgos (obstrução de vias aéreas), queimaduras, envenenamentos e agressões ${ }^{(2)}$.

As mortes por causas externas ocupam o terceiro lugar no ranking de mortalidade geral no Brasil, principalmente quando se trata da população mais jovem, do sexo masculino e economicamente ativa, causando ainda grande impacto socioeconômico no país ${ }^{(3,4)}$.

Cabe destacar que as bases de dados nacionais sobre mortalidade, embora já possuam valores bem expressivos, ainda apresentam cobertura insatisfatória em ampla área, havendo subnotificação de óbitos no Norte e Nordeste do Brasil ${ }^{(5)}$.

A partir dessas informações, visualiza-se a importância da utilização de medidas de primeiros socorros e de prevenção de acidentes ${ }^{(6)}$. O tema ainda não é muito difundido, prevalecendo, na maioria das vezes, o pouco conhecimento acerca do assunto, embora os populares tenham o potencial para salvar vidas ou diminuir chances de sequela nas situações de urgência ou emergência( ${ }^{(7)}$.

Apesar de poucos trabalhos mostrarem o nível de conhecimento de comunitários, em 2016, um estudo na cidade de Juiz de Fora, Minas Gerais, Brasil, investigou o conhecimento de leigos sobre o suporte básico de vida (SBV) e obteve como resultado que $41 \%$ sabiam o que era é SBV, entretanto apenas $5,8 \%$ afirmaram que se sentiam preparados para realizá-lo ${ }^{(7)}$.

Os primeiros socorros são as primeiras estratégias utilizadas em uma vítima acidentada antes que ela receba atendimento especializado de saúde, e têm o objetivo de manter os sinais vitais e garantir a vida ${ }^{(8)}$. É importante salientar que essas medidas são temporárias e não substituem um atendimento médico posterior, mas contribuem de forma significativa com o ganho de tempo até a chegada da vítima em uma unidade de saúde ${ }^{(8)}$.

Vale ressaltar que o socorro prestado de maneira equivocada pode causar mais danos à vítima, ato caracterizado como negligência. Por isso, mostra-se cada vez mais considerável o ensino sobre primeiros socorros e prevenção de acidentes, uma forma eficaz e concreta de promoção de saúde ${ }^{(9)}$.

Essa problemática torna-se ainda mais agravante quando se tratam de regiões rurais distantes, por conta do difícil acesso à orientação, à capacitação e aos serviços hospitalares ${ }^{(10)}$. Embora a saúde seja um direito de todos ${ }^{(10)}$, ainda existem desigualdades sociais, culturais e regionais que tornam brasileiros com pouca ou nenhuma acessibilidade a esse direito. No Amazonas, por exemplo, existem, aproximadamente, 40 mil ribeirinhos, que carecem de unidades de saúde, principalmente pela dificuldade de acesso à região amazônica. Esses povoados isolados ficam à beira dos rios do maior estado brasileiro em área territorial|(11).

A Política Nacional de Promoção de Saúde tem por objetivo "promover a equidade e a melhoria das condições e dos modos de viver, ampliando a potencialidade da saúde individual e coletiva e reduzindo vulnerabilidades e riscos à saúde"(12). Pensando nisso, um projeto de extensão, composto por acadêmicos de Medicina de uma universidade 
pública do Amazonas, proporciona a disseminação de conhecimentos sobre primeiros socorros em situações de urgência e emergência como forma de promoção de saúde para a população leiga. Não só na cidade de Manaus, mas também no meio rural, as ações de extensão realizadas pelo projeto permitem a capacitação de populares para atuação correta nesses cenários, qualificando-os por meio de palestras, treinamentos e simulações realísticas.

A partir dessa realidade, o presente trabalho, portanto, tem por objetivo relatar a experiência de um projeto de extensão universitária acerca de primeiros socorros e prevenção de acidentes em uma ação de capacitação da população ribeirinha.

\section{SÍNTESE DOS DADOS}

O projeto de extensão está ligado à PróReitoria de Extensão da Universidade e sua temática abrange cuidados em primeiros socorros e prevenção de acidentes. As atividades do projeto se iniciaram em 1997 e mantém-se ativo até os dias atuais. É composto por acadêmicos de Medicina, cujo ingresso no projeto é conquistado mediante a realização de uma prova teórico-prática ${ }^{(13)}$. O projeto tem sua base no campus universitário, localizado na cidade de Manaus, tendo aproximadamente 40 membros ativos e mais de 100 egressos. As atividades do grupo estão voltadas para a realização de palestras em escolas, igrejas, academias, shoppings centers, empresas privadas, hospitais e comunidades, e também para a realização de simulações realísticas para treinamento.

Este relato é um estudo descritivo referente à experiência prática de cinco acadêmicos do projeto na disseminação de informações acerca de primeiros socorros e prevenção de acidentes numa comunidade ribeirinha às margens do baixo Rio Negro, comunidade Santa Maria do Rio Negro, em outubro de 2015. O convite foi feito pela Prefeitura Municipal de Manaus, por meio da Casa Militar/Secretaria Executiva de Proteção e Defesa Civil. Utilizando uma embarcação fornecida pela prefeitura, a viagem iniciava-se no período da manhã, durando cerca de 4 horas, saindo do porto de Manaus.

Para os ribeirinhos, o rio é a única rua, e as embarcações, os únicos meios de transporte, o que torna mais difícil o acesso a esses locais ${ }^{(13)}$. Além da dificuldade de locomoção, carecem de saúde e educação. As palestras, treinamentos e simulações foram realizados na única escola municipal do local. O público presente, por sua vez, englobava uma amostra ampla, desde crianças a idosos, de ambos os sexos, na faixa etária de 10 a 65 anos, totalizando 35 pessoas pertencentes aos núcleos familiares da comunidade.

Como em todas as palestras ministradas pelos acadêmicos do projeto em questão, os temas abordados foram: introdução ao socorro, reanimação cardiopulmonar, obstrução de vias aéreas, afogamento, convulsão, intoxicação, queimaduras, sangramentos e acidente vascular encefálico, cujo foco principal era a orientação da correta intervenção diante desses acidentes, bem como as estratégias de prevenção dessas intercorrências ${ }^{(14)}$.

As palestras foram preparadas minuciosamente para a compreensão do público leigo, não sendo utilizados termos técnicos e específicos da Medicina. Anualmente, os integrantes do projeto reeditam esses materiais teóricos com a finalidade de estarem atualizados de acordo com as diretrizes que regem as condutas de primeiros socorros, tais como os protocolos do Ministério da Saúde e de associações internacionais, como a American Heart Association (AHA).

Exibiram-se apresentações com auxílio de aparelhos projetores, as quais eram alternadas com simulações realizadas pelos integrantes do projeto. Após cada exposição teórica, realizava-se um treinamento prático relativo a cada tema, os quais são mostrados abaixo:

\section{Introdução ao Socorro}

As palestras iniciaram-se com o tema de "Introdução ao socorro", explicando-se sobre o que são os primeiros socorros e qual sua importância, de maneira bem ilustrada. O projeto mostrou a relevância de um atendimento rápido ao doente na primeira hora após o acidente, pois o paciente precisa ser tratado numa unidade de saúde, fator determinante na modificação do prognóstico, conceito definido como golden hour (hora de ouro) ${ }^{(15,16)}$.

$\mathrm{Na}$ introdução ao socorro também se informaram características que determinam um bom socorrista, como bom senso, técnica, responsabilidade e espírito de liderança ${ }^{(15,16)}$. Finalizou-se o tema com os cinco passos do socorro, um guia fácil organizado pelos acadêmicos do projeto. Esses cinco passos organizam o modo de pensar dos leigos e como devem agir diante de uma situação de emergência, servindo de substrato para todos os temas da sequência. Os passos são: 1) segurança, 2) sinalização/isolamento, 3) avaliação da vítima, 4) chamar por socorro e 5) ajudar a vítima. Os passos, nessa formatação, foram criados pelo próprio projeto em um contexto mais didático, baseando-se em guidelines do ATLS e PHTLS.

Na segurança, o leigo precisa entender que a garantia da sua segurança é tão essencial quanto a da vítima ${ }^{(15)}$, 
então ele deve se certificar de que está num local seguro, que não corre risco de se contaminar ou de causar mais acidentes. Para que se sinta seguro, ele pode acionar outros serviços, telefonando aos bombeiros (193), polícia (190) ou defesa civil (199), de acordo com a necessidade da situação.

No segundo passo, sinalização/isolamento, foi destacado o isolamento da vítima em situações de aglomeração. Para isso, os acadêmicos ensinaram a fazer um cordão humano de isolamento com auxílio dos comunitários. Em seguida, instruiu-se a comunidade a como sinalizar, se necessário, a presença da vítima no local do acidente ${ }^{(15,16)}$.

O terceiro passo, avaliação da vítima, o projeto sempre considera um dos pontos mais importantes. É quando o popular terá seu primeiro contato com a vítima. Os acadêmicos ensinaram o público a identificar se o doente responde e respira através de manobras de verificação da responsividade e de atividade respiratória instruída, como tocar o ombro da vítima e chamá-lo com voz firme e em volume audível, e inclinar-se na lateral da vítima e visualizar movimentos torácicos de inspiração e expiração, com os olhos ao nível do tórax. O projeto não ensinou a palpação de pulsos como identificação de sinal vital, visto que as novas atualizações de suporte básico de vida para leigos também não fazem citação, reservando tal ato para profissionais de saúde ${ }^{(17)}$.

Após a avaliação da vítima é a hora de chamar o socorro. Os acadêmicos insistiram em fazer a comunidade memorizar o número do Serviço de Atendimento Móvel de Urgência (SAMU), pois é a garantia de que a vítima tenha a abordagem de um profissional de saúde. Em algumas cidades ribeirinhas, como é o caso da comunidade Santa Maria do Rio negro, o serviço do SAMU é fluvial, em lanchas conhecidas popularmente como "ambulanchas", veículos especificamente destinadas ao socorro rápido e resgate médico de pacientes através dos rios ${ }^{(18)}$.

Após ser definida a sequência, os acadêmicos perguntavam repetidamente quais eram esses cinco passos aos populares, com o objetivo de se certificar que fixaram tal conteúdo. Salienta-se que essa ordem foi utilizada para todos os assuntos seguintes, por isso tamanha importância. As diversas situações e cenários que os populares poderiam se deparar foram simuladas pelos acadêmicos ao longo da explanação dos temas, contando com aparato de maquiagem e manequins de simulação(19-21).

\section{Reanimação Cardiopulmonar (RCP)}

O segundo tema abordado foi RCP. Os dados epidemiológicos quanto à ocorrência de parada cardiorrespiratória (PCR) no Brasil são insuficientes, entretanto estima-se que as PCRs com mais chances de reversão (com o ritmo de taquicardia ventricular) ocorram em ambiente extrahospitalar, portanto, ressalta-se a importância do conhecimento dos populares sobre RCP e sua técnica correta ${ }^{(22)}$.

Durante esse assunto, foi detalhada a identificação da vítima com PCR pela irresponsividade e, após a identificação, o chamado por socorro(18). Sobre a técnica, o grupo explanou como fazer uma RCP de qualidade, priorizando a sequência "hands only", realizando compressões torácicas efetivas apenas com as mãos, sequenciais, profundas $(5-6 \mathrm{~cm})$ e rápidas (100-120compressões/minuto). Portanto, sem a administração de incursões respiratórias. Falou-se a respeito da importância do retorno do tórax, ritmo e minimização de interrupções da massagem cardíaca( ${ }^{(22)}$.

Os acadêmicos destacaram a importância do uso do desfibrilador externo automático (DEA) no aumento das chances de sobrevivência do doente e ensinaram a usá-lo corretamente, se disponível. Estima-se que o uso do aparelho de choque precocemente, por leigos, aumenta chances de viver em aproximadamente $85 \%{ }^{(23-25)}$.

Foi conferida ênfase especial ao treinamento prático das habilidades de RCP, utilizando-se dorso de manequins adultos, da linha Prestan, com sensor de LED para avaliação da qualidade das manobras, e também manequins bebê de corpo inteiro. Além disso, utilizou-se um simulador de desfibrilador externo automático, para que os comunitários pudessem entender como é o funcionamento e praticar seu uso.

\section{Obstrução de Vias Aéreas}

Uma das principais causas de obstrução das vias aéreas no Amazonas é a espinha do peixe, alimento mais consumido na região. No primeiro semestre de 2016, cerca de 900 pessoas procuraram atendimento médico para retirada do corpo estranho da via aérea apenas na cidade de Manaus ${ }^{(26)}$.

Os acadêmicos do projeto destacaram a importância de estimular a tosse, em caso de obstrução, e de realizar a manobra de Heimlich, se necessário ${ }^{(27)}$, relembrando a possibilidade de RCP caso o doente entre em PCR. A manobra é o melhor método pré-hospitalar de desobstrução das vias aéreas superiores e é realizada por meio de compressões abdominais, na vítima em pé, até que o objeto tenha sido expelido ${ }^{(27)}$. Os instrutores do projeto também alertaram para a possibilidade de obstrução das vias aéreas de bebês e demonstraram a técnica correta de desobstrução para o público. 


\section{Afogamento}

No Amazonas, os últimos números deixam mais nítida a mortalidade por causas externas, um exemplo são os afogamentos. A Sociedade Brasileira de Salvamento Aquático (SOBRASA), no boletim de 2018, divulgou o Amazonas como um dos quatro estados brasileiros onde houve aumento da porcentagem de óbitos por afogamento, com uma elevação de $12,51 \%$ nos anos de 1998 a 2016. Um valor extremamente alto, já que houve estados com média de redução de $30 \%$ desses óbitos ${ }^{(28)}$.

Em virtude dos dados acima, os acadêmicos pontuaram de maneira reforçada medidas de prevenção ao afogamento e ensinaram as devidas condutas de primeiros socorros diante de um caso. Entre as medidas, podem ser citadas: utilizar materiais para tentar trazer a vítima à superfície, posicioná-la para recuperação, aquecer a vítima e, caso a vítima evolua para PCR, iniciar RCP(15,16).

\section{Convulsão}

A convulsão é um distúrbio causado por um aumento excessivo da atividade elétrica das células neuronais, ocasionando movimentos desordenados, repetitivos e rápidos em todo o corpo ${ }^{(29)}$.

Devido aos sinais e sintomas da crise convulsiva, é possível que grande parte dos leigos tenha dificuldade em prestar algum auxílio. Por isso, o projeto instruiu a respeito de como proceder nos casos de crise convulsiva: manter a calma, marcar o horário de início, afastar objetos e móveis, apoiar a cabeça do doente e não tentar segurar a língua dele(15,16).

\section{Intoxicação}

O consumo de agrotóxico no estado do Amazonas, em 2009, ultrapassou o valor de 282 toneladas de princípios ativos (89\% herbicidas) em quase 185.000 hectares de área plantada, sendo notificados 14 casos de intoxicação por agrotóxicos, $4 \%$ dos casos totais da região Norte(30).

Quanto à intoxicação, falou-se sobre quais materiais de uso comum poderiam levar à intoxicação, como: ácido, soda cáustica, desodorante, produtos químicos em geral. Em seguida, os acadêmicos informaram sobre o Disque-Intoxicação (0800- 722- 6001) $)^{(31)}$, um contato gratuito para solicitar ajuda ou esclarecer dúvidas a respeito do tema. Além disso, destacou-se que devem levar imediatamente a vítima para uma unidade de saúde, para que as devidas condutas médicas possam ser tomadas.

\section{Queimaduras}

A temática de queimaduras é interessante para a comunidade, pois grande parcela dos leigos se baseia em condutas incorretas. As lesões por queimadura possuem um risco significativo de mortalidade, além de danos permanentes físicos, funcionais e traumas psíquicos nos que sobrevivem. As principais vítimas de queimadura são as crianças, geralmente menores de cinco anos ${ }^{(32)}$.

Os acadêmicos reforçaram medidas preventivas e os respectivos primeiros socorros, os quais consistem em afastar a fonte de calor e lavar o local lesionado com água corrente em temperatura ambiente. O projeto insistiu em lembrar à comunidade para não passar produtos comestíveis e outros, como dentifrício (pasta de dente) sobre a queimadura. Além disso, destacaram a importância de não estourar as bolhas que eventualmente possam ser formadas e, em caso de queimaduras mais graves, procurar atendimento em unidade de saúde da região ${ }^{(33)}$.

\section{Sangramentos}

No tema de sangramentos, falou-se a respeito dos sangramentos mais leves e mais intensos, além de sangramentos oral, nasal e no ouvido. Os acadêmicos ressaltaram a importância das fases do socorro, sendo a primeira delas a segurança. Dessa forma, salientaram aos comunitários que não entrassem em contato com as secreções e/ou sangue da vítima, visando a proteção contra doenças infecciosas transmissíveis ${ }^{(3)}$. Para isso, destacaram o uso de materiais que podem ser utilizados na substituição de outros, como utilizar sacos plásticos nas mãos caso o socorrista não possua luvas(33).

\section{Acidente vascular cerebral (AVC)}

O AVC é a segunda principal causa de morte no mundo, segundo a Organização Mundial de Saúde. No Brasil, está cotada como a principal causa de morte, seguida por infarto agudo do miocárdio ${ }^{(34-36)}$. Estima-se que, até 2030, o AVC continue sendo a principal causa de morte e, a partir desses dados, percebe-se a necessidade de dar orientações quanto ao tema ${ }^{(37)}$. 
O projeto destacou os dois tipos de AVC, isquêmico e hemorrágico, de maneira lúdica. Após isso, mostrou aos comunitários uma forma simples de identificar uma pessoa que esteja possivelmente com AVC, utilizando-se o mnemônico SOLL (Sorrir - Ouvir - Levantar os braços - Ligar para o 192), baseado na escala de Cincinnati. A partir dessa escala, interpreta-se que haja $72 \%$ de probabilidade para AVC se um desses sinais for anormal. Caso existam dois achados anormais, as chances aumentam para $85 \%{ }^{(35)}$.

A comunidade ribeirinha se mostrou extremamente acolhedora e colaborativa desde o primeiro contato dos acadêmicos, mostrando interesse e reconhecimento da necessidade da informação acerca dos temas. Houve grande troca de conhecimentos e explanação de dúvidas com o público local, de forma que o vínculo estabelecido entre comunitários e acadêmicos permitiu crescimento mútuo e a promoção da saúde.

O desenvolvimento de tal atividade em uma comunidade ribeirinha permitiu que o grupo de estudantes constatasse que, para a formação e condução de leigos nos temas de primeiros socorros, há a necessidade de explorá-los de maneira simplificada, com mais exemplos, tornando-os acessíveis para o entendimento de todos, sendo apresentados de maneira didática e, às vezes, beirando o informal.

\section{CONCLUSÃO}

Observou-se a importância da disseminação de informações para a comunidade ribeirinha para ações em situações de urgência e emergência por meio de atividades educativas de prevenção e simulação de conduta, pois se percebeu que o acesso a informações confiáveis sobre a maneira apropriada de atuação diante de acidentes em comunidades distantes é ainda limitado.

Ao introduzir essa proposta de ensino aos ribeirinhos ressalta-se que a experiência permitiu aos acadêmicos exercer influência sobre a realidade social desta comunidade, contribuindo para a prevenção de agravos de saúde. Para os alunos foi possível visualizar o processo de ensino e a elaboração de palestras com material educativo mais acessível para pessoas com baixa escolaridade e pouco acesso a informação, provando ser necessário que assuntos relativos à saúde ganhem contexto maior dentro da realidade local.

Por fim, afirma-se que todos os aprendizados e experiências foram importantes para a instrução do restante dos membros do projeto de extensão universitária, bem como a manutenção de projetos e parcerias que permitam continuar com participações de instrução em primeiros socorros em outras comunidades ribeirinhas do Amazonas.

\section{CONFLITOS DE INTERESSE}

Os autores atestam a inexistência de conflitos de interesses.

\section{AGRADECIMENTOS}

Os autores agradecem à coordenação docente e discente, aos médicos egressos e aos acadêmicos ativos no referido projeto de extensão e à PróReitoria de Extensão da universidade.

\section{CONTRIBUIÇÕES}

Maria Giovana Queiroz de Lima contribuiu com a elaboração e delineamento do estudo; a aquisição, análise e interpretação dos dados; e a redação e/ou revisão do manuscrito. Ronaldo Almeida Lidório Júnior contribuiu com a aquisição, análise e interpretação dos dados; e a redação e/ou revisão do manuscrito. Bruna Natália Serrão Lins Pinto, Luma Ximenes de Oliveira, Amanda Ellen de Morais e Laísa Ezaguy de Hollanda contribuíram com a aquisição, análise e interpretação dos dados.

\section{REFERÊNCIAS}

1. Fraxe TJP, Pereira HS, Witkoski AC. Comuni - dades ribeirinhas amazônicas: modos de vida e uso dos recursos naturais. Manaus: EDUA; 2007.

2. Gonsaga RAT, Rimoli CF, Pires EA, Zogheib FS, Fujino MFT, Cunha MB. Avaliação da mortalidade por causas externas. Rev Col Bras Cir. 2012;39(4):263-7.

3. Costa MJC, Mangueira JO. Perfil epidemiológico de ocorrência no trânsito no Brasil - Revisão integrativa. SANRE Sobral. 2014;13(2):110-6. 
4. Preis LC, Lessa G, Tourinho FSV, Santos JLG. Epidemiologia da mortalidade por causas externas no período de 2004 a 2013. Rev Enferm UFPE [Internet]. 2018 [acesso em 2019 Set 21];12(3):716-28. Disponível em: https://periodicos.ufpe.br/revistas/revistaenfermagem/article/view/230886/28032

5. Ministério da Saúde (BR). DATASUS. Taxa de mortalidade específica por causas externas [Internet]. 2012 [acesso em 2019 Set 21]. Disponível em: http://tabnet.datasus.gov.br/cgi/tabcgi.exe?idb2012/c09.def

6. Reveruzzi B, Buckley L, Sheehan M. School-Based First Aid Training Programs: A Systematic Review. J Sch Health. 2016; 86(4):266-72.

7. Chehuen JA Neto, Brum IV, Pereira DR, Santos LG, Moraes SL, Ferreira RE. Conhecimento e Interesse sobre Suporte Básico de Vida entre Leigos. Int J Cardiovasc Sci. 2016;29(6):443-2.

8. Ragadali A Filho, Pereira NA, Leal I, Anjos QS, Loose JTT. A Importância do treinamento de primeiros socorros no trabalho. Rev Saberes [Internet]. 2015 [acesso 2019 Set 21];3(2):114-25. Disponível em: https:// facsaopaulo.edu.br/wp-content/uploads/sites/16/2018/05/ed3/10.pdf

9. Silva CR, Carvalho BG, Cordoni L Jr, Nunes EFPA. Dificuldade de acesso a serviços de média complexidade em municípios de pequeno porte: um estudo de caso. Ciênc Saúde Colet [Internet]. 2017 [acesso em 2019 Set 19];22(4):1109-20. Disponível em: http://www.scielo.br/scielo.php?pid=S141381232017002401109\&script=sci_abstract\&tIng=pt

10. Constituição da República Federativa do Brasil de 1988 [Internet]. [2016] [acesso em 2019 Set 19]. Disponível em: http://www.planalto.gov.br/ccivil_03/Constituicao/Constituicao.htm

11. França R. Nas vilas ribeirinhas do Amazonas, 37 mil pessoas carecem de médicos e saneamento. O Globo [Internet]. 2014 [acesso em 2019 Set 20]. Disponível em: https://oglobo.globo.com/sociedade/nas-vilasribeirinhas-do-amazonas-37-mil-pessoas-carecem-de-medicos-saneamento-14635488

12. Ministério da Saúde (BR). Política Nacional de Promoção da Saúde [Internet]. $3^{\mathrm{a}}$ ed. Brasília: Ministério da Saúde; 2010 [acesso em 2019 Set 15]. Disponível em: http://bvsms.saude.gov.br/bvs/publicacoes/politica_ nacional_promocao_saude_3ed.pdf

13. Nunes A, Albuquerque D, Adriana M. Projeto Alfa-Manaus: desde 1997 ajudando a salvar vidas. Anais do $2^{\circ}$ Congresso Brasileiro de Extensão Universitária; 2004 Set 12-15; Belo Horizonte, Br. Belo Horizonte: UFMG; 2004.

14. Franco EC, Santo CE, Arakawa AM, Xavier A, França ML, Oliveira NA, et al. Promoção da saúde da população ribeirinha da região amazônica: relato de experiência. Rev CEFAC. 2015;17(5):1521-30.

15. Prehospital Trauma Life Support (PHTLS) atendimento pré-hospitalar ao traumatizado. $8^{\mathrm{a}}$ ed. Amsterdã: Elsevier; 2017.

16. Leles AS, Bezerra BJS. Primeiros Socorros. [Brasília]: NT Editora; 2015.

17. American Heart Association. Destaques das Diretrizes da American Heart Association 2015 para RCP e ACE. Chicago: Amerian Heart Association; 2015.

18 'Ambulanchas' vão fazer socorro rápido a ribeirinhos no Rio Negro, no Amazonas. O Globo [Internet]. 2009 [acesso em 2019 Set 21]. Disponível em: https://oglobo.globo.com/brasil/ambulanchas-vao-fazer-socorrorapido-ribeirinhos-no-rio-negro-no-amazonas-3154030

19. Silva JK, Conceição DMM, Rodrigues GM, Dantas GSV. Suporte básico de vida para leigos: relato de atividades extensionistas. Rev Ciênc Ext [Internet]. 2017 [acesso em 2019 Set 19];13(1):190-203. Disponível em: https://ojs.unesp.br/index.php/revista_proex/article/view/1383/1327

20. Freitas TPP, Paula CC, Zanon BP, Meirelles FSC, Weiller TH, Padoin SMM. Contribuições da extensão universitária na formação de acadêmicos de enfermagem. Rev Enferm UFSM [Internet]. 2016 [acesso em 2019 Set 28];6(3):307-16. Disponível em: https://periodicos.ufsm.br/reufsm/article/view/19966/pdf

21. Deslandes MSS, Arantes AR. A extensão universitária como meio de transformação social e profissional. Sinapse Múltipla. 2017;6(2):179-83.

22. Bernoche C, Timerman S, Polastri TF, Giannetti NS, Siqueira AWS, Piscopo A, et al. Atualização da Diretriz de Ressuscitação Cardiopulmonar e Cuidados de Emergência da Sociedade Brasileira de Cardiologia 2019. Arq Bras Cardiol. 2019;113(3):449-663. 
23. Zandomenighi $C$, Martins EAP. Análise epidemiológica dos atendimentos de parada cardiorrespiratória. Rev Enferm UFPE [Internet]. 2018 [acesso em 2019 Set 21];12(7):1912-22. Disponível em: https://periodicos.ufpe. $\mathrm{br} /$ revistas/revistaenfermagem/article/view/230822

24. Ministério da Saúde (BR), Departamento de Informática do SUS. Indicadores de mortalidade: taxa de mortalidade por doenças do aparelho circulatório [Internet]. 2013 [acesso em 2019 Set 21]. Disponível em: http://datasus.saude.gov.br/

25. Lai H, Choong CV, Fook-Chong S, Ng YY, Finkelstein EA, Haaland B, et al. Interventional strategies associated with improvements in survival for out-of-hospital cardiac arrests in Singapore over 10 years. Resuscitation. 2015;89:155-61.

26. Bittencourt PFS, Camargos PAM. Aspiração de corpos estranhos. J Pediatr. 2002;77(1):9-18.

27. Espinhas de peixe levaram 900 ao médico no $1^{\circ}$ semestre, segundo Susam. D24am Amazonas [Internet]. 2016 [acesso em 2019 Set 21]. Disponível em: https://d24am.com/noticias/espinhas-de-peixe-levaram-900ao-medico-no-1-semestre-segundo-susam/

28. Szpilman D. Afogamentos: o que está acontecendo? [Internet]. 2018 [acesso em 2019 Set 21]. Disponível em: http://www.sobrasa.org/new_sobrasa/arquivos/baixar/AFOGAMENTOS_Boletim_Brasil_2018.pdf

29. Honjoya MMB, Ribeiro PPM. Crise convulsiva relato de um treinamento. Braz J Surg Clin Res. 2017;20(1):104-7.

30. Ministério da Saúde (BR). Sistema Nacional de Vigilância em Saúde: Relatório de Situação - Amazonas [Internet]. 2011 [acesso em 2019 Set 21]. Disponível em: http://bvsms.saude.gov.br/bvs/publicacoes/sistema_ nacional_vigilancia_saude_am_5ed.pdf

31. Agência Nacional de Vigilância Sanitária. Disque Intoxicação [Internet]. 2019 [acesso em 2019 Set 21]. Disponível em: http://portal.anvisa.gov.br/disqueintoxicaao

32. Meschial WC, Sales CCF, Oliveira MLF. Fatores de risco e medidas de prevenção das queimaduras infantis: revisão integrativa da literatura. Rev Bras Queimaduras. 2016;15(4):267-73.

33. Karren KJ, Hafen BQ, Limmer D, Mistovich JJ. Primeiros socorros para estudantes. 10ª ed. [São Paulo]: Manole; 2013.

34. World Health Organization. The top 10 causes of death [Internet]. 2014 [acesso em 2019 Set 21]. Disponível em: https://www.who.int/news-room/fact-sheets/detail/the-top-10-causes-of-death

35. Araújo JP, Darcis JVV, Tomas ACV, Mello WA. Tendência da mortalidade por acidente vascular cerebral no Município de Maringá, Paraná entre os anos de 2005 a 2015. Int J Cardiovasc Sci. 2018;31(1):56-62.

36. Ribeiro AL, Duncan BB, Brant LC, Lotufo PA, Mill JG, Barreto SM. Cardiovascular health in Brazil: trends and perspectives. Circulation. 2016;133(4):422-33.

37. World Health Organization. Health statistics and information systems: projections of mortality and causes of death, 2015 and 2030 [Internet]. 2013 [acesso em 2019 Set 21]. Disponível em: http:// www.who.int/ healthinfo/global_burden_disease/projections/em

38. Ministério da Saúde (BR), Secretaria de Atenção à Saúde, Departamento de Atenção Especializada. Manual de rotinas para atenção ao AVC [Internet]. 2013 [acesso em 2019 Set 21]. Disponível em: http://bvsms.saude. gov.br/bvs/publicacoes/manual_rotinas_para_atencao_avc.pdf

\section{Endereço para correspondência:}

Maria Giovana Queiroz de Lima

Universidade Federal do Amazonas

Av. General Rodrigo Octavio Jordão Ramos, 1200

Bairro: Coroado I

CEP: 69067-852 - Manaus - AM - Brasil

E-mail: mariagiovanalima@gmail.com

Como citar: Lima MGQ, Oliveira LX, Morais AE, Pinto BNSL, Hollanda LE, Lidório RA Júnior. Disseminação de informações sobre primeiros socorros e prevenção de acidentes em uma comunidade ribeirinha. Rev Bras Promoç Saúde. 2020;33:10053. 